\title{
Gambaran Faktor Risiko Penderita Osteoartritis Lutut di Instalasi Rehabilitasi Medik RSUP Prof. Dr. R. D. Kandou Manado Periode Januari -Juni 2017
}

\author{
${ }^{1}$ Ayling Soeryadi \\ ${ }^{2}$ Joudy Gessal \\ ${ }^{2}$ Lidwina S. Sengkey
${ }^{1}$ Program Studi Pendidikan Dokter Fakultas Kedokteran Universitas Sam Ratulangi Manado
${ }^{2}$ Bagian Instalasi Rehabilitasi Medik RSUP Prof. Dr. R. D. Kandou
Email: anvina.ayling@gmail.com

\begin{abstract}
Osteoarthritis (OA) is a chronically progressive degenerative joint disease associated with joint cartilage damage. It is usually affected the joints of the hands, vertebrae, hips, and knee which is reported as the most common affected location. Risk factors of OA are divided into non-modifiable factors and modifiable factors. The non-modifiable risk factors are age, gender, race, and genetic factors, while the modifiable factors are body mass index, occupation, knee injury, blood pressure, blood sugar level, and cholesterol level. This study was aimed to determine the non-modifiable risk factors and modifiable risk factors in patients with knee OA at the Medical Rehabillitation Unit of Prof. Dr. R. D. Kandou Hospital Manado. This was a quantitative descriptive study using medical record data in the Medical Rehabilitation Unit. There were 36 cases of knee OA during the period of January-June 2017; 27 cases had complete medical record data. The highest distribution of knee OA were patients in the 70-79 age group (33.3\%), females (70.4), Minahasa ethnic (59.3\%), no family history of OA (70.4\%), BMI $\geq 23(66.7 \%)$, retired (51.9\%), history of knee injury (77.8\%), prehypertension (51.9\%), no history of DM (70.4\%) and of hypercholesterolemia (66.7\%). Conclusion: Based on the non-modifiable risk factors, females were more at risk of developing knee $\mathrm{OA}$ and based on modifiable risk factors, knee injury was the most common factor in the occurrence of knee OA.
\end{abstract}

Keywords: knee osteoarthritis, risk factors

\begin{abstract}
Abstrak: Osteoartritis (OA) merupakan penyakit sendi degeneratif yang berkaitan dengan kerusakan kartilago sendi dan bersifat kronik-progresif. Lokasi yang biasanya terkena adalah sendi pada tangan, vertebra, panggul dan lutut, dimana lutut dilaporkan sebagai lokasi yang paling sering terkena. Faktor risiko OA terbagi atas faktor yang dapat di modifikasi dan faktor yang tidak dapat di modifikasi. Faktor risiko yang tidak dapat dimodifikasi ialah antara lain umur, jenis kelamin, suku/ras dan genetik. Faktor risiko yang dapat dimodifkasi berupa indeks massa tubuh, pekerjaan, cedera/trauma, tekanan darah, gua darah, dan kadar kolesterol dalam darah. Penelitian ini bertujuan untuk mengetahui faktor risiko yang tidak dapat dimodifikasi maupun dapat dimodifikasi pada penderita OA lutut di Instalasi Rehabilitasi Medik RSUP Prof. Dr.R. D. Kandou Manado. Jenis penelitian ialah deskriptif kuantitatif menggunakan data rekam medik di Instalasi Rehabilitasi Medik. Terdapat 36 kasus OA lutut selama periode Januari-Juni 2017; hanya 27 kasus yang memiliki data rekan medik lengkap. Pada penelitian didapatkan distribusi OA lutut terbanyak pada kelompok usia 70-79 tahun $(33,3 \%)$, jenis kelaimin perempuan $(70,4 \%)$, suku Minahasa (59,3\%), tidak memiliki riwayat OA dalam keluarga $(70,4 \%)$, IMT $\geq 23(66,7 \%)$, pensiunan $(51,9 \%)$, riwayat cedera lutut $(77,8 \%)$, tekanan darah pre-hipertensi $(51,9 \%)$, tanpa riwayat DM $(70,4 \%)$ dan riwayat hiperkolesterolemia $(66,7 \%)$. Simpulan : Berdasarkan distribusi faktor risiko yang tidak dapat dimodifikasi, jenis kelamin perempuan paling rentan terhadap OA lutut dan berdasarkan faktor risiko yang dapat dimodifikasi, cedera/trauma lutut merupakan faktor yang paling sering.
\end{abstract}

Kata kunci: osteoatritis lutut, faktor risiko 
Osteoartritis (OA) adalah penyakit degeneratif yang melibatkan kartilago, lapisan sendi, ligamen dan tulang sehingga dapat menyebabkan kekakuan sendi. Perjalanan penyakit biasanya lambat, namun dapat menyebabkan nyeri sendi hebat hingga disabilitas berupa kegagalan gerak sendi. ${ }^{1}$ Gejala klinis yang ditimbulkan berupa nyeri sendi terutama saat beraktifitas dan berkurang saat istirahat, ${ }^{2,3}$ kaku sendi pada pagi hari yang biasanya kurang dari 30 menit, $^{2}$ krepitasi, hambatan pergerakan sendi, pembesaran sendi, hingga perubahan gaya berjalan. OA menyerang sendi pada tangan, lutut, panggul, tulang belakang, dan dapat juga menyerang lebih dari satu sendi. ${ }^{3}$

OA merupakan penyakit sendi yang paling sering terjadi. ${ }^{4,5} \mathrm{Di}$ Indonesia prevalensi penyakit sendi yang didiagnosis oleh tenaga kesehatan mengalami peningkatan seiring dengan bertambahnya usia. Prevalensi tertinggi terjadi pada usia $\leq 75$ tahun. $^{6}$ Di China, OA merupakan penyebab utama dari disabilitas pada kelompok usia $>40$ tahun. $^{7}$ Angka kejadian osteoartritis di Indonesia sejak tahun 1990 hingga 2010 telah mengalami peningkatan yang menyebabkan peningkatan beban kesehatan yang di ukur dengan DALY (Disability Adjust Lost Years) sebanyak 44,2\%. Tahun-tahun kehilangan kualitas hidup pada OA yang diukur berdasarkan DALY per 100.000 laki-laki dan perempuan mencapai puncak pada usia 80 tahun. Pada tahun 2013, OA berdasarkan DALY per 100.000 perempuan mencapai puncak pada 1.327,4 tahun dibandingkan pada laki-laki yang hanya 907,7 tahun $^{8}$

Penyebab pasti dari OA tidak diketahui namun berdasarkan sejumlah penelitian diketahui penyebabnya multifaktorial. Faktor risiko utama pada OA ialah usia, jenis kelamin perempuan, obesitas, aktivitas fisik, faktor genetik, ras, trauma sendi, dan chondrocalcinosis. Kurang bergerak, obesitas dan penyakit metabolisme seperti diabetes dapat memperparah OA. Osteoartritis juga lebih sering terjadi pada kelompok perempuan usia peri-menopause yang memiliki kadar estrogen rendah, berat badan berlebih, dan masih aktif bekerja. ${ }^{1}$

Osteoartritis masuk dalam jajaran sepuluh besar penyakit yang paling banyak menimbulkan kecacatan pada negara-negara industri. Pada Global Burden of Diasease tahun 2010, OA lutut dan panggul menempati urutan ke-11 sebagai penyebab kecacatan terbanyak secara global. ${ }^{9}$ Di Amerika Serikat, lebih dari 30 juta orang didiagnosis dengan OA. ${ }^{5}$ Osteoartritis juga merupakan penyebab utama kehilangan pekerjaan di Amerika Serikat dan menghabiskan dana sebanyak 100 miliar dollar Amerika setiap tahunnya. ${ }^{10,11}$

Pada ekstremitas bawah, osteoarthritis paling sering mengenai sendi lutut. ${ }^{2}$ Data pada Rumah Sakit Al-Islam Bandung pada tahun 2014 menunjukkan sebanyak 487 pasien yang mengalami OA lutut primer dan $82,54 \%$ diantaranya berjenis kelamin perempuan, dan paling banyak terjadi pada kelompok usia 56-65 tahun. ${ }^{12}$ Sementara data pada Instalasi Rehabilitasi Medik di RSUP Prof. Dr. R. D. Kandou Manado pada tahun 2016 menunjukkan OA menduduki urutan ke-4 dari daftar penyakit terbanyak dengan jumlah sebanyak 348 kunjungan.

Penelitian ini bertujuan untuk mendapatkan gambaran faktor risiko pada penderita oa lutut di RSUP Prof. Dr. R. D. Kandou Manado.

\section{METODE PENELITIAN}

Jenis penelitian ialah deskriptif kuantitatif melalui pendekatan retrospektif dengan desain potong lintang menggunakan data sekunder dari rekam medik pasien OA lutut di Instalasi Rehabilitasi Medik RSUP Prof. Dr. R. D. Kandou Manado pada periode Januari-Juni 2017. Penelitian dilakukan pada bulan September-November 2017. Variabel penelitian ialah usia, jenis kelamin, suku, riwayat OA dalam keluarga, indeks massa tubuh (IMT), pekerjaan, riwayat cedera lutut, tekanan darah, riwayat diabetes melitus (DM), dan riwayat hiperkolesterolemia.

\section{HASIL PENELITIAN}

Pada periode Januari-Juni 2017 didapatkan 36 pasien yang didiagnosis dengan OA lutut; hanya 27 data pasien yang memenuhi kriteria inklusi.

Tabel 1 menunjukkan penderita OA 
lutut periode Januari-Juni 2017 yang berusia 30-39 tahun sebanyak 1 orang $(3,7 \%), 40-49$ tahun sebanyak 1 orang $(3,7 \%), 50-59$ tahun sebanyak 7 orang $(25,9 \%)$, 60-69 tahun sebanyak 6 orang $(22,2 \%), 70-79$ tahun yaitu 9 orang $(33,3 \%)$, dan usia $\geq 80$ tahun 3 orang $(11,1 \%)$.

Tabel 1. Distribusi penderita OA lutut berdasarkan usia

\begin{tabular}{ccc}
\hline \multirow{2}{*}{ Usia (tahun) } & \multicolumn{2}{c}{ Jumlah } \\
& $\mathbf{N}$ & $\mathbf{\%}$ \\
\hline $30-39$ & 1 & 3,7 \\
$40-49$ & 1 & 3,7 \\
$50-59$ & 7 & 25,9 \\
$60-69$ & 6 & 22,2 \\
$70-79$ & 9 & 33,3 \\
$\geq 80$ & 3 & 11,1 \\
Jumlah & 27 & 100 \\
\hline
\end{tabular}

Penderita OA lutut paling banyak berjenis kelamin perempuan yaitu sebanyak 19 orang $(70,4 \%)$ sedangkan yang berjenis kelamin laki-laki sebanyak 8 orang $(29,6 \%)$.

Tabel 2. Distribusi OA lutut menurut jenis kelamin

\begin{tabular}{ccc}
\hline \multirow{2}{*}{ Jenis kelamin } & \multicolumn{2}{c}{ Jumlah } \\
& N & \% \\
\hline Laki-laki & 8 & 29,6 \\
Perempuan & 19 & 70,4 \\
Jumlah & 27 & 100 \\
\hline
\end{tabular}

Osteoartritis lutut paling banyak ditemukan pada suku Minahasa yaitu sebanyak 16 orang $(59,3 \%)$, suku SangiheTalaud sebanyak 3 orang $(11,1 \%)$, suku Bantik 1 orang (3,7\%), suku BolaangMongondow 1 orang $(3,7 \%)$, suku Gorontalo 2 orang $(7,4 \%)$, suku Jawa 2 orang $(7,4 \%)$, suku Bali 1 orang $(3,7 \%)$, dan suku Arab 1 orang $(3,7 \%)$.

Distribusi penderita OA lutut berdasarkan riwayat genetik OA dalam keluarga didapatkan sebanyak 8 orang yang memiliki riwayat genetik OA dalam keluarga $(29,6 \%)$ dan yang tidak memiliki riwayat genetik OA dalam keluarga yaitu 19 orang $(70,4 \%)$.
Tabel 3. Distribusi penderita OA lutut berdasarkan suku

\begin{tabular}{ccc}
\hline \multirow{2}{*}{ Suku } & \multicolumn{2}{c}{ Jumlah } \\
& N & \% \\
\hline Minahasa & 16 & 59,3 \\
Sangihe-Talaud & 3 & 11,1 \\
Bantik & 1 & 3,7 \\
Bolaang-Mongondow & 1 & 3,7 \\
Gorontalo & 2 & 7,4 \\
Jawa & 2 & 7,4 \\
Bali & 1 & 3,7 \\
Arab & 1 & 3,7 \\
Jumlah & 27 & 100 \\
\hline
\end{tabular}

Tabel 4. Distribusi penderita OA lutut berdasarkan riwayat OA dalam keluarga

\begin{tabular}{ccc}
\hline $\begin{array}{c}\text { Riwayat OA dalam } \\
\text { keluarga }\end{array}$ & \multicolumn{2}{c}{ Jumlah } \\
N & \% \\
\hline Ya & 8 & 29,6 \\
Tidak & 19 & 70,4 \\
Jumlah & 27 & 100 \\
\hline
\end{tabular}

Berdasarkan IMT dari 27 penderita OA lutut, hanya 1 orang $(3,7 \%)$ yang memiliki IMT underweight, 8 orang $(29,6 \%)$ IMT normal, 6 orang $(22,2 \%)$ overweight, 5 orang $(18,5 \%)$ obese-1, dan 7 orang obese-2 $(25,9 \%)$.

Tabel 5. Distribusi penderita OA lutut berdasarkan Indeks Massa Tubuh (Kriteria Asia Pasifik)

\begin{tabular}{ccc}
\hline \multirow{2}{*}{ IMT } & \multicolumn{2}{c}{ Jumlah } \\
& $\mathbf{N}$ & $\mathbf{\%}$ \\
\hline Underweight & 1 & 3,7 \\
Normal & 8 & 29,6 \\
Overweight & 6 & 22,2 \\
Obese 1 & 5 & 18,5 \\
Obese 2 & 7 & 25,9 \\
Jumlah & 27 & 100 \\
\hline
\end{tabular}

Berdasarkan data pada rekam medis, dari 27 orang penderita OA lutut yang memenuhi kriteria inklusi didapatkan sebanyak 14 orang (51,9\%) merupakan pensiunan, sebanyak 5 orang $(18,5 \%)$ ibu 
rumah tangga, sebanyak 3 orang $(11,1 \%)$ swasta, sebanyak 1 orang $(3,7 \%)$ wiraswasta, dan PNS 4 orang $(14,8 \%)$

Tabel 6. Distribusi penderita OA lutut berdasarkan pekerjaan

\begin{tabular}{ccc}
\hline \multirow{2}{*}{ Pekerjaan } & \multicolumn{2}{c}{ Jumlah } \\
& N & \% \\
\hline Pensiunan & 14 & 51,9 \\
IRT & 5 & 18,5 \\
Swasta & 3 & 11,1 \\
Wiraswasta & 1 & 3,7 \\
PNS & 4 & 14,8 \\
Jumlah & 27 & 100 \\
\hline
\end{tabular}

Dari 27 orang penderita OA lutut memenuhi kriteria inklusi, sebanyak 21 orang $(77,8 \%)$ diantaranya memiliki riwayat cedera dan sebanyak 6 orang $(22,2 \%)$ tidak memiliki riwayat cedera.

Tabel 7. Distribusi penderita OA lutut berdasarkan riwayat cedera

\begin{tabular}{ccc}
\hline $\begin{array}{c}\text { Riwayat cedera } \\
\text { lutut }\end{array}$ & \multicolumn{2}{c}{ Jumlah } \\
N & \% \\
\hline Ya & 21 & 77,8 \\
Tidak & 6 & 22,2 \\
Jumlah & 22 & 100 \\
\hline
\end{tabular}

Data pada tabel diatas menunjukkan penderita OA lutut yang memiliki tekanan darah normal sebanyak 9 orang $(33,3 \%)$, terbanyak pada prehipertensi yaitu 14 orang $(51,9 \%)$, dan hipertensi stage 1 sebanyak 4 orang $(14,8 \%)$.

Tabel 8. Distribusi penderita OA lutut berdasarkan tekanan darah

\begin{tabular}{ccc}
\hline \multirow{2}{*}{ Tekanan darah } & \multicolumn{2}{c}{ Jumlah } \\
& N & \% \\
\hline Normal & 9 & 33,3 \\
Prehipertensi & 14 & 51,9 \\
Hipertensi stage 1 & 4 & 14,8 \\
Jumlah & 27 & 100 \\
\hline
\end{tabular}

Dari 27 subjek penelitian yang memenuhi kriteria inklusi, didapatkan sebanyak 8 orang $(29,6 \%)$ memiliki riwayat diabetes melitus dan lebih banyak pada mereka yang tidak memiliki riwayat diabetes melitus yaitu 19 orang $(70,4 \%)$.

Tabel 9. Distribusi penderita OA lutut berdasarkan riwayat diabetes melitus

\begin{tabular}{ccc}
\hline $\begin{array}{c}\text { Riwayat diabetes } \\
\text { melitus }\end{array}$ & \multicolumn{2}{c}{ Jumlah } \\
\hline Ya & \% \\
\hline Tidak & 19 & 29,6 \\
Jumlah & 27 & 70,4 \\
\hline
\end{tabular}

Data pada Tabel 10 menunjukkan sebanyak 9 orang $(33,3 \%)$ penderita OA lutut memiliki riwayat hiperkolesterolemia dan 18 orang $(66,7 \%)$ tidak memiliki riwayat hiperkolesterolemia.

Tabel 10. Distribusi penderita OA lutut berdasarkan riwayat hiperkolesterolemia

\begin{tabular}{ccc}
\hline Riwayat & \multicolumn{2}{c}{ Jumlah } \\
hiperkolesterolemia & N & \% \\
\hline Ya & 9 & 33,3 \\
Tidak & 18 & 66,7 \\
Jumlah & 27 & 100 \\
\hline
\end{tabular}

\section{BAHASAN}

Dari hasil penelitian didapatkan penderita OA lutut yang datang ke Instalasi Rehabilitasi Medik selama periode Januari Juni 2017 terbanyak pada kelompok usia 7079 tahun (33,3\%). Angka tersebut jauh lebih besar dibanding pada kelompok usia 40-49 tahun $(3,7 \%)$ dan kelompok usia 30-39 tahun $(3,7 \%)$. Hal ini sejalan dengan penelitian di daerah pedesaan Gaoyou China yang melaporkan bahwa prevalensi keseluruhan OA lutut meningkat secara bermakna seiring bertambahnya usia, mencapai $25 \%$ pada perempuan dan $24,7 \%$ pada laki-laki pada kelompok usia $\geq 70$ tahun. ${ }^{13}$

Angka harapan hidup di Provinsi Sulawesi Utara yang cukup tinggi, yaitu mencapai 71,02 tahun pada tahun 2016, ${ }^{14}$ menjadi faktor yang berkaitan dengan banyaknya kelompok usia 70-79 tahun $(33,3 \%)$ pada penderita OA lutut yang 
datang di Instalasi Rehabilitasi Medik RSUP Prof. R.D. Kandou Manado.

Pada penelitian ini didapatkan OA lutut lebih sering terjadi pada perempuan $(70,4 \%)$ daripada laki-laki $(29,6 \%)$. Penelitian ini selaras dengan penelitian yang dilakukan di Poliklinik Ortopedi Rumah Sakit Al Islam Bandung yang melaporkan angka kejadian OA lutut primer lebih tinggi secara drastis pada perempuan $(82,54 \%){ }^{12}$ Tingginya angka kejadian OA pada perempuan pada penelitian ini sesuai dengan teori yang menyatakan bahwa faktor hormonal memegang peranan penting dalam terjadinya OA.

Berdasarkan suku, mayoritas penderita OA lutut berasal dari suku Minahasa $(59,3 \%)$. Angka tersebut jauh lebih besar jika dibandingkan dengan suku lainnya. Suku Minahasa, Bolaang-Mongondow, SangiheTalaud, dan Bantik merupakan suku-suku yang berasal dari Provinsi Sulawesi Utara, dimana suku Minahasa merupakan suku mayoritas, sedangkan suku Gorontalo, Bali, Jawa, dan Arab merupakan suku pendatang. Tingginya angka kejadian OA lutut pada penderita dengan asal suku Minahasa dapat disebabkan karena Minahasa merupakan suku mayoritas yang mendiami Provinsi Sulawesi Utara, atau dapat juga disebabkan karena faktor genetik pada suku Minahasa. Penelitian lebih lanjut dibutuhkan untuk analisis faktor genetik pada suku Minahasa.

Berdasarkan riwayat OA dalam keluarga, penderita OA lutut yang datang di Instalasi Rehabilitasi Medik RSUP. Prof.DR. R. D. Kandou Manado lebih banyak yang tidak memiliki riwayat OA dalam keluarga $(70,4 \%)$. Hal ini tidak sejalan dengan penelitian yang dilakukan oleh Bhaskar et al. ${ }^{1}$ pada perempuan di daerah pedesaan Kerala, India tahun 2016 yang menyatakan bahwa riwayat OA dalam keluarga berpengaruh secara bermakna terhadap angka kejadian OA lutut (OR:1,78).

Pada penelitian ini didapatkan penderita OA lutut yang memiliki IMT underweightnormal (33,3\%), sedangkan sisanya memiliki kategori IMT overweight-obese tipe 2 $(66,7 \%)$. Hal ini sejalan dengan penelitian yang di lakukan oleh Pal et al. ${ }^{15}$ di India, dimana prevalensi OA lutut secara bermakna
$(P=0,007)$ lebih rendah pada kelompok IMT underweight dibanding yang memiliki IMT obese. Hasil penelitian ini sesuai dengan teori yang menyatakan bahwa berat badan berlebih dapat menjadi faktor risiko OA lutut akibat beban mekanik tubuh yang lebih berat.

Pada penelitan didapatkan mayoritas penderita OA lutut ialah pensiunan $(51,9 \%)$. Penelitian ini sejalan dengan penelitian cohort yang dilakukan oleh Kiadaliri et al. ${ }^{16}$ di Swedia yang mendapatkan penderita OA lebih banyak terjadi pada pensiunan $(80,9 \%)$ dibanding mereka yang masih bekerja. Hasil penelitian ini sesuai dengan teori yang menyatakan bahwa orang yang hanya beraktivitas ringan dan jarang bergerak, seperti pada pensiunan rentan terhadap OA lutut dibanding pada orang yang masih bekerja. Banyaknya populasi pensiunan pada penelitian ini juga diakibatkan oleh faktor usia karena pensiunan merupakan lansia .

Pada penelitian ini, penderita OA lutut yang datang di RSUP Prof.R.D. Kandou Manado didominasi oleh penderita yang memiliki riwayat cedera pada lutut sebelumnya $(77,8 \%)$. Hal ini sesuai dengan penelitian yang dilakukan oleh Bhaskar et $\mathrm{al}^{1}$ pada perempuan di daerah pedesaan Kerala, India yang mendapatkan OA lutut lebih sering terjadi pada kelompok yang memiliki riwayat cedera lutut sebelumnya dibandingkan yang tidak pernah mengalami cedera lutut, $(\mathrm{OR}=1,51)$. Hal ini turut membuktikan bahwa cedera/trauma lutut merupakan faktor yang berpengaruh pada kejadian OA lutut.

Hasil penelitian menunjukkan penderita OA lutut lebih banyak terjadi pada kelompok dengan tekanan darah pre-hipertensi $(51,9 \%)$, dibanding tekanan darah normal $(33,3 \%)$ dan hipertensi stage 1 (14,8\%). Secara keseluruhan penelitian ini menunjukkan bahwa penderita dengan tekanan darah normal $(33,3 \%)$ lebih sedikit dibanding penderita OA yang datang dengan tekanan darah pre hipertensi-hipertensi stage 1 (66,7\%). Hal ini selaras dengan yang dididapatkan pada penelitian di Korea Selatan, dengan jumlah sampel yang lebih banyak, yaitu prevalensi OA lutut lebih besar pada penderita yang mengalami hipertensi dibanding penderita yang tidak mengalami hipertensi (OR 1,26). ${ }^{17}$ 
Hal tersebut sesuai dengan teori yang menyatakan bahwa hipertensi dapat menjadi faktor risiko OA.

Berdasarkan data pada penelitian ini, OA lutut lebih sering terjadi pada penderita yang tidak memiliki riwayat diabetes melitus (70,4\%). Pada penelitian yang dilakukan di Gaoyou China dengan jumlah sampel yang lebih besar juga didapatkan OA lutut lebih banyak terjadi pada kelompok non-diabetes baik pada laki-laki maupun perempuan. Penelitian ini sejalan dengan yang dilakukan di Poli Interna RSD Dr. Soebandi Jember, dimana disimpulkan bahwa tidak terdapat hubungan kadar glukosa darah dan osteoartritis lutut $(P=0,90),{ }^{18}$ dan tidak selaras dengan penelitian yang dilakukan di Divisi Orthopaedi Departemen Bedah RSUP H. Adam Malik Medan dan RSUD dr. Pringadi, Medan yang menyatakan bahwa penderita DM tipe 2 tiga kali lebih berisiko untuk mengalami OA lutut $(P=0,002$; OR 3,957). ${ }^{19}$

Berdasarkan data penelitian, OA lutut lebih sering terjadi pada penderita tanpa riwayat hiperkolesterolemia (66,7\%). Eymard et al. ${ }^{20}$ juga mendapatkan hal serupa pada penelitiannya dimana OA lutut pada penderita yang memiliki riwayat dislipidemia hanya sebesar $27,6 \%$.

\section{SIMPULAN}

Dari hasil penelitian ini dapat disimpulkan bahwa osteoartritis lutut paling banyak didapatkan pada kelompok usia 7079 tahun, jenis kelamin perempuan, suku Minahasa, tidak memilki riwayat OA dalam keluarga, status gizi overweight-obese 2 atau pada IMT $\geq 23$, pensiunan, riwayat cedera/ trauma lutut sebelumnya, pre-hipertensi, dan tanpa riwayat diabetes melitus dan hiperkolesterolemia.

Berdasarkan faktor risiko yang tidak dapat dimodifikasi, jenis kelamin perempuan paling rentan terhadap OA lutut sedangkan berdasarkan faktor risiko yang dapat dimodifikasi, cedera/trauma lutut menjadi faktor yang paling sering pada OA lutut.

\section{SARAN}

Dibutuhkan pencatatan data rekam medis yang lebih lengkap sehingga sistem dokumen-tasi di Instalasi Rehabilitasi Medik dapat lebih baik.

Perlu dilakukan penelitian lanjut dengan metode analitik dan mencakup populasi yang lebih luas untuk mengetahui kekuatan korelasi antara faktor risiko dengan angka kejadian OA lutut.

Perlu memeriksakan diri sedini mungkin bagi yang telah memiliki keluhan menyerupai gejala OA lutut, terlebih bagi yang memliki faktor risiko OA lutut.

Disarankan mengedukasi masyarakat untuk menghindari faktor-faktor risiko yang dapat dimodifikasi, terutama cedera lutut.

\section{DAFTAR PUSTAKA}

1. Bhaskar A, Areekal B, Vasuvedan B, Ajith R, Ravi S, Sankar S. Osteoarthritis of knee and factors associated with it in middle aged women in a rural area of central Kerala, India. Int J Community Med Public Health. 2016;3:2926-31.

2. Sein M, Wilkins AN, Philips EM. Knee osteoarthritis In: Frontera WR, Silver JK, Rizzo Jr TD, editors. Essentials of Physical Medicine and Rehabilitation (3rd ed). Philadelphia: Elsevier Saunders, 2015; p. 361-8.

3. Soeroso J, Isbagio $\mathbf{H}$, Kalim $\mathbf{H}$, Broto $\mathbf{R}$, Pramudiyo R. Osteoartritis. In: Setiati S, Alwi I, Sudaya AW, Simadibrata M, Setiyahadi B, Syam AF, editors. Buku Ajar Ilmu Penyakit Dalam (6the ed). Jakarta: Interna Publishing, 2015; p. 3199-211.

4. Plotnikoff R, Karunamuni N, Lytvyak E, Penfold C, Schopflocher D, Imayama I, et al. Osteoarthritis prevalence and modifiable factors: a population study. BMC Public Health. 2015;15:1195-204.

5. Centers for Disease Control and Prevention (CDC). Osteoarthritis. 2017 Jul 6 [cited 2017 Sep 28]. Available from: https://www.cdc.gov.arthritis/basics/oste oarthritis

6. Badan Penelitian dan Pengembangan Kesehatan, Kementrian Kesehatan RI. Riset Kesehatan Dasar 2013.

7. Shen J, Chen D. Recent progress in osteoarthritis research. J Am Acad Orthop Surg. 2014;22:467-8.

8. Global burden of disease study. Osteoarthritis in Indonesia: statistic on overall impact 
and specific effect on demographic groups. 2016 Jul 21 [cited 2017 Sep 23]. Available from: http://global-diseaseburden.healthgrove.com/1/76301/Osteoa rthritis-in-Indonesia

9. Cross SF, Hoy D, Nolte S, Ackerman I, Fransen M, et al. The global burden of hip and knee osteoarthritis: estimates from the global burden of disease 2010 study. Ann Rheum Dis. 2014;73:132330.

10. Sandel LJ. Etiology of osteoarthritis: genetics and synovial joint development. Nat Rev Rheumatol. 2012;8:77-89.

11. Centers for Disease Control and Prevention (CDC). Prevalence of doctor-diagnosed arthritis and arthritis attributable activity limitation -United States, 2010-2012. MMWR Morb Mortal Wkly Rep. 2013;62:869-73.

12. Sonjaya MR. Karakteristik pasien osteoartritis primer di Poliklinik Ortopedi Rumah Sakit Al-Islam Bandung tahun 2014 [Skripsi]. Bandung: Universitas Islam Bandung; 2014.

13. Liu Y, Zhang H, Liang N, Fan W, Li J, Huang $\mathbf{Z}$, et al. Prevalence and associated factors of knee osteoarthritis in a rural Chinese adult population: an epidemiological survey. BMC Public Health. 2016;16:94-101.

14. Badan Pusat Statistik Provinsi Sulawesi Utara. Indikator strategis: angka harapan hidup Provinsi Sulawesi Utara 2016. [cited 2017 Nov 30]. Available from:
https://sulut.bps.go.id/QuickMap

15. Pal CP, Singh P, Chaturvedi S, Pruthi KK, Vij A. Epidemiology of knee osteoarthritis in Indiaand related factors. Indian J Orthop. 2016;50:518-22.

16. Kiadaliri AA, Lamm CJ, de Verdier MG, Engstrom G, Turkiewicz A, Lohmander LS, et al. Association of knee pain and different of knee osteoarthritis with health-related quality of life: a population-based cohort study in southern Sweden. Health and Quality of Life Outcomes. 2016;14:121-7.

17. Kim HS, Shin JS, Lee J, Lee YJ, Kim M, Bae YH, et al. Association between knee osteoarthritis, cardiovascular risk factors, and the framingham risk score in South Koreans: a cross sectional study. Plos One. 2016;1:1-13.

18. Astutik FH, Santoso A, Hairuddin. Hubungan kendali glukosa darah dengan osteoarthritis lutut pada pasien DM di RSD Dr Soebandi. Jurnal Pustaka Kesehatan. 2014;2:221-5.

19. Budiman BE. Hubungan kejadian osteoartritis lutut dengan diabetes melitus tipe 2 di RSUP H. Adam Malik dan RSUD Dr. Pirngadi Medan [Tesis]. Medan: Universitas Sumatera Utara; 2016.

20. Eymard F, Parsons C, Edwards MH, PetitDop F, Reginster JY, Bruyere O, et al. Diabetes is a risk factor for knee osteoarthritis progression. Osteoarthritis and Cartilage. 2015;23:851-9. 